\title{
DIREITO AO ESQUECIMENTO E O SUPERINFORMACIONISMO: APONTAMENTOS NO DIREITO BRASILEIRO DENTRO DO CONTEXTO DE SOCIEDADE DA INFORMAÇÃO
}

\author{
ANTONIO RULLI JÚNIOR \\ ANTONIO RULLI NETO
}




\title{
DIREITO AO ESQUECIMENTO E O SUPERINFOR- MACIONISMO: APONTAMENTOS NO DIREITO BRASILEIRODENTRODOCONTEXTODESOCIEDADE DA INFORMAÇÃO
}

Recebimento: $14 / 08 / 2013$

Aceite: $28 / 10 / 2013$

Antonio Rulli Júnior ${ }^{1}$

Antonio Rulli Neto ${ }^{2}$

\section{RESUMO}

O texto trata do direito ao esquecimento em meio a um contexto de excesso de informações que acaba sendo lançado na internet, concluindo pela possibilidade de limitação e exclusão de informações, considerando-se os direitos fundamentais.

Palavras-Chave: Sociedade da informação. Direito ao esquecimento. Direitos fundamentais. Efetivismo.

\begin{abstract}
The essay analizes the right to be alone in a context of excessive information released on the internet and concludes by the possibility of limitation and exclusion of information, considering the fundamental rights.
\end{abstract}

Keywords: Information society. Right to be alone. Fundamental rights. Efectivism.

\footnotetext{
1 Desembargador TJSP. Professor Universitário, Bacharel em Ciências Jurídicas e Sociais pela Faculdade de Direito da USP. Mestre e Doutor em Direito pela PUC-SP.

2 Doutor em Direito pela Faculdade de Direito da Universidade de São Paulo e pela Faculdade de Direito da PUC-SP, Coordenador Ajunto do Programa de Mestrado em Direito da Sociedade da Informação do Centro Universitário da FMU.
} 


\section{O ATUAL CONTEXTO}

O contexto atual sobre a informação, ao passo que é de muita importância para as relações sociais, econômicas e educacionais, caminha ao lado de questionamentos elementares como de que maneira tornar o ambiente informacional digno e de acordo com os princípios e direitos fundamentais.

Dentre os questionamentos que surgem, um dos quais merece reflexão é o do direito ao esquecimento. Quanto tempo uma informação pode ou deve ficar disponível? E, além disso, qual informação deve ou não ser disponibilizada.

Não se está aqui, ressalte-se, fazendo alusão à censura, mas aos limites da informação, seja de qual fonte for.

Aliás, o discurso de censura, ligado à liberdade de imprensa e expressão, nem sequer pode passar por aqui. Este escrito volta-se, especialmente, ao problema de informações pessoais e interpessoais, a própria liberdade das pessoas em informarem, serem informadas e, mesmo, não serem informadas ou não terem informações suas divulgadas.

Trata-se da discussão acerca do alcance da dignidade e do right to be alone.

A velocidade como as informações circulam e não permitem mais se pense tão somente em mecanismos de abstenção ou repressão, mas de meios eficazes para evitar os abusos e excluí-los, ou impedir que gerem prejuízos continuados ou mais gravosos.

A mesma velocidade com que se dissemina uma 
informação costuma ser aquela em que se esquece daquela situação, desde que apagada dos meios de informação.

Explica-se: Quanto tempo pode-se manter uma informação negativa? Quanto tempo se pode noticiar algo sobre uma pessoa, seja positivo ou negativo, e o que se pode manter de informação sobre alguém?

Nas palavras de Castells: "O nosso mundo está em processo de transformação estrutural desde há duas décadas. É um processo multidimensional, mas está associado à emergência de um novo paradigma tecnológico, baseado nas tecnologias de comunicação e informação, que começaram a tomar forma nos anos 60 e que se difundiram de forma desigual por todo o mundo. Nós sabemos que a tecnologia não determina a sociedade: é a sociedade. A sociedade é que dá forma à tecnologia de acordo com as necessidades, valores e interesses das pessoas que utilizam as tecnologias. Além disso, as tecnologias de comunicação e informação são particularmente sensíveis aos efeitos dos usos sociais da própria tecnologia. A história da Internet fornecenos amplas evidências de que os utilizadores, particularmente os primeiros milhares, foram, em grande medida, os produtores dessa tecnologia"'.

Sociedade da informação é todo esse contexto, como dito, que muda e dita comportamentos e o funcionamento da sociedade. Seus efeitos alteraram as formas de comunicação, os 
relacionamentos interpessoais, os relacionamentos, as formas de trabalho, o consumo e a própria vida em sociedade.

\section{AS REFLEXÕES ACERCA DO SUPERINFORMA- CIONISMO}

Essas reflexões voltam-se a um fenômeno da modernidade e do que se denomina de sociedade da informação - o superinformacionismo.

O superinformacionismo cria uma verdadeira massa de informações sobre tudo e sobre todos, queiram ou não estar naqueles conjuntos de dados ou informações.

Qual é o limite desse superinformacionismo? Sem dúvida um parâmetro para sua limitação são os direitos fundamentais e a lei.

O superinformacionismo é esse contexto em que nos encontramos. Uma busca na internet diz mais que somos do que nós mesmos imaginamos. E não são apenas os dados que se coletam com facilidade, mas até mesmo os dados de acesso que nos expõem.

Até que ponto pode ser divulgada, invadida, destruída ou desnudada a personalidade de cada um de nós? Quanto tempo uma pessoa pode pagar por um crime, mais que aquele em que permanece numa prisão?

Eis os pontos de reflexão nos quais nos concentraremos nos itens seguintes. 


\section{DIREITO DE EXPRESSÃO, À INFORMAÇÃO, INFORMAR E SER INFORMADO}

O direito à liberdade de expressão e à informação são fundamentais e estão na Constituição:

Art. $5^{\circ}$ Todos são iguais perante a lei, sem distinção de qualquer natureza, garantindo-se aos brasileiros e aos estrangeiros residentes no País a inviolabilidade do direito à vida, liberdade, igualdade, segurança e a propriedade, nos termos seguintes:

IV - é livre a manifestação do pensamento, sendo vedado o anonimato;

VIII - ninguém será privado de direitos por motivo de crença religiosa ou de convicção filosófica ou política, salvo se as invocar para eximir-se de obrigação legal a todos imposta e recusar-se a cumprir prestação alternativa, fixada em lei;

IX - é livre a expressão da atividade intelectual, artística, científica e de comunicação, independentemente de censura ou licença

Art. $220^{\circ}$ A manifestação do pensamento, a criação, a expressão e a informação, sob qualquer forma, processo ou veículo não sofrerão qualquer restrição, observado o disposto nesta Constituição.

$\S 2^{\circ}$ - É vedada toda e qualquer censura de natureza política, ideológica e artística.

Tanto a liberdade de expressão, como o direito de informação derivam da Constituição, mas ambos são distintos.

Apesar de a Constituição deixar muito ampla a proteção ao direito de expressar-se, informar e ser informado, o importante é se perceber que há um limite à expressão e à informação. Esse 
mesmo limite que existe também se aplica ao critério temporal de uma informação.

O direito de expressão é livre, diga-se, mas seu exercício tem limitações. Não se pode, por exemplo, por discordar de alíquotas de impostos, sair nu pela avenida Paulista para protestar. Mas se pode fazer tal protesto se estiver trajado.

$\mathrm{O}$ direito de expressão deriva de atos próprios. Já o direito de informar pode derivar de atos ou fatos relacionados a terceiros, o ato de informar (normalmente) é só divulgativo, não compreendendo uma ação propriamente material direta e sim formal. Ambos têm suas limitações.

Alexandre de Moraes foca a ideia, demonstrando haver limitações:

"O direito de receber informações verdadeiras é um direito de liberdade e caracteriza-se essencialmente por estar dirigido a todos os cidadãos, independentemente de raça, credo ou convicção político-filosófica, com a finalidade de fornecimento de subsídios para a formação de convicções relativas a assuntos públicos. A proteção constitucional às informações verdadeiras também engloba as eventualmente errôneas ou não comprovadas em juízo, desde que não tenha havido comprovada negligência ou má-fé por parte do informador. A Constituição Federal não protege as informações levianamente não verificadas ou austuciosas e propositadamente errôneas, transmitidas com total desrespeito à verdade, pois as liberdades públicas não podem prestar-se a tutela de condutas ilícitas. A proteção constitucional à informação é relativa, havendo necessidade de distinguir as informações de fato de interesse público, da vulneração de condutas 
íntimas e pessoais, protegidas pela inviolabilidade à vida privada, e que não podem ser devassadas de forma vexatória ou humilhante." 4

\title{
Para José Afonso da Silva:
}

\begin{abstract}
“15.4 Liberdade de informação jornalística - É nesta que se centra a liberdade de informação, que assume características modernas, superadoras da velha liberdade de imprensa. Nela se concentra a liberdade de informar, e é nela ou através dela que se realiza o direito coletivo à informação, isto é, a liberdade de ser informado. Por isso, é que a ordem jurídica que lhe confere um regime específico que lhe garanta a atuação e lhe coíba os abusos. A propósito da liberdade de imprensa cabe recordar estas palavras de Marx: "a imprensa livre é o olhar onipotente do povo, a confiança personalizada do povo nele mesmo, o vínculo articulado que une o indivíduo ao Estado e ao mundo, a cultura incorporada que transforma lutas materiais em lutas intelectuais, e idealiza suas formas brutas. É a franca confissão do povo a si mesmo, e sabemos que o poder da confissão é o de redimir. A imprensa livre é o espelho intelectual, no qual o povo se vê, e a visão de si mesmo é a primeira confissão da sabedoria." ${ }^{5}$ (...)."
\end{abstract}

\section{Como já dito, as mesmas limitações que existem para informar, existem para o tempo que tais informações serão divulgadas.}

\footnotetext{
4 Constituição do Brasil Interpretada e Legislação Constitucional Editora Jurídico. São Paulo: Atlas, $4^{\mathrm{a}}$ edição, p. 252.

5 Curso de Direito Constitucional Positivo. São Paulo: Malheiros editores $-14^{\mathrm{a}}$ edição - pg. 239.
} 


\section{O DIREITO AO ESQUECIMENTO}

O direito ao esquecimento não pode ser visto como delírio moderno.

No Direito Penal esse direito é mais fácil de ser visualizado e existe há tempos. Pensemos no seguinte - um sujeito comete um crime, é julgado, condenado e cumpre a pena. Seus registros sobre esse fato não podem ser permanentemente utilizados contra esse sujeito.

Isso não ocorre apenas nos casos de condenação, mas também em situações nas quais o sujeito não tem condenação, mas acaba condenado pela informação.

Vamos mais além: Uma pessoa é vitima de crime sexual. Tal fato vai para a rede. Quanto tempo isso pode ser mantido? E as referências sobre tal fato? E alguém que tenha sido demitido por justa causa, por exemplo? Deve permanentemente ter tal informação, por mais verdadeira que seja, mantida na rede? Ou seja, o sujeito comete um erro, como todos nós podemos cometer, mas fica permanentemente manchado e condenado, ainda que indiretamente.

Isso não pode ocorrer, pois estaríamos falando em tratamento degradante, vedado pela Constituição ${ }^{6}$. A pessoa é tão atingida que não tem como conseguir uma segunda chance, nem mesmo sobreviver autonomamente. Não se pode confundir existência de pena com necessário processo precedente, pois,

$6 \quad \mathrm{CF}$, art. $5^{\circ}$. inc. III :"'ninguém será submetido a tortura nem a tratamento desumano ou degradante" Vide ainda CF art. $1^{\circ}$, inc. III. 
na prática, se tem uma verdadeira pena sem processo. O sujeito é punido pela sociedade, mesmo inocente ou sem ter sido processado, sentindo os efeitos da pena. De qualquer maneira, o tratamento degradante não pode ocorrer.

Por isso, o direito ao esquecimento é um direito fundamental à dignidade da pessoa humana e à inviolabilidade pessoal (inciso III dos arts. $1^{\circ}, 5^{\circ}, \mathrm{X}$, da CF, arts. 93 e 748 do CPP).

O direito ao esquecimento normalmente é associado ao direito penal, mas também deve ser associado ao direito em geral e aos meios midiáticos.

Mesmo que culpado, mesmo que tenha errado, o sujeito não pode ser condenado mais de uma vez pelo mesmo crime, além de não poder ser condenado por toda a vida - todas as penas, por uma questão de dignidade, não podem existir para sempre.

Mesmo aquele que erra não pode ser penalizado para sempre e não pode ser submetido a tratamento degradante, seja pelo Estado ou pelos particulares.

Acerca da eficácia dos direitos fundamentais no direito privado, o posicionamento atual é bastante receptivo nesse sentido. O direito ao esquecimento, tratado no direito norteamericano como "the right to be alone", é aquele em que se garante que os dados sobre uma pessoa somente serão conservados de maneira a permitir a identificação do sujeito a eles ligado, além de somente poder ser mantido durante o tempo necessário para suas finalidades. 
O Decreto n. 3505, de 2000, instituiu a Política de Segurança da Informação nos órgãos e entidades da Administração Pública Federal e regula situações nas quais a Administração, especificamente, tem relação com a informação.

De outro modo, não há um tempo preciso, nem as informações que podem ou não permanecer na rede, apenas interpretação dos tribunais. Por isso, falta o estabelecimento de critérios temporais para a permanência de informações.

Não se fala aqui de sites de relacionamento unicamente, mas da informação em geral, porque hoje é muito fácil coletar informações sobre as pessoas na internet. Os meios midiáticos modernos não permitem ao cidadão o direito ao esquecimento, especialmente a internet.

Não é só o esquecimento, mas o policiamento que pode surgir daí. O preconceito e a desigualdade, o policiamento ideológico e social, a covardia. Ficaríamos obrigados a pensar como a maioria. Seria o fim da individualidade e da autodeterminação pessoal, a própria liberdade de expressão pode ficar comprometida. Esse é o perigo da virtuosa informação, quando se está diante de oportunistas. Mesmo que se possa cobrar deles depois, o estrago já está feito.

Imagine-se que um possível empregador possa acessar informações e deixar de contratar alguém por entender ser imoral participar de uma comunidade, ter religião diversa etc. É o preconceito.

Diante de todas essas questões, é importante estabelecer limites ou lineamentos, ponderando-se valores e a 
proporcionalidade e a razoabilidade são um possível caminho para evitar os exageros.

O caminho não é violar o princípio da publicidade, nem criar meios de censura, mas não se podem violar os princípios da intimidade, vida e dignidade, violando-se, por consequência, o direito ao esquecimento.

É importante também lembrar que visão coletiva pode se levar para uma ou outra opinião, nem sempre coincidente com os direitos fundamentais. Não são raros os casos em que uma coletividade ataca um indivíduo incessantemente, seja por seu comportamento, seja por sua opinião ou, mesmo, por sua própria apresentação ou sua figura.

Surge daí o direito ao esquecimento, tendo os meios de divulgação de informação o dever de excluir aquele conteúdo.

\section{O CONTEXTO EFETIVISTA}

Ao longo das últimas décadas, foram muitos os movimentos desenvolvidos para dar efetividade ou reconhecer a necessidade do funcionamento do direito de maneira célere; respostas adequadas e transparentes que venham em tempo aproveitável, levando-se em conta os direitos fundamentais.

Os mais recentes movimentos do pensamento apontam alguns caminhos. A chamada pós-modernidade, comentada por alguns autores ${ }^{7}$, influenciou o direito com uma necessária 
reflexão da sociedade. Aliás, dentre os juristas brasileiros quem, com muita profundidade analisou o tema da nova hermenêutica constitucional foi o professor Luis Roberto Barroso. Temos algumas necessidades prementes e uma emenda constitucional (Emenda 45, de 2004) que traz em seu bojo o necessário efetivismo com o qual o judiciário deve lidar. ${ }^{8}$

Tal evolução não é uma novidade, mas uma tendência. Como lidar com tanta velocidade e um sistema de normas como o nosso? Muitas têm sido as contribuições no campo jurídico. Pensemos nessas mudanças em mais de 20 anos de Constituição, além de tantas reformas no direito processual e no direito material. Temos um novo código civil e uma série de reformas processuais que alteraram profundamente, desestruturando, inclusive, o modelo processual clássico. $\mathrm{E}$ isso não seria uma mistura das disciplinas jurídicas, mas exatamente uma confluência e busca de um objetivo comum: a vida digna, em última análise. Ao lado da efetividade que pode ser uma forma de se trabalhar (trabalhar com efetividade), o efetivismo é um movimento mais amplo e congruente, um ponto de intersecção entre direito, processo, sociedade e jurisdição. Tanto o direito, como a sociedade e as instituições tendem a congruir para a busca de um cenário digno para as pessoas.

O potencial de transformação está estabelecido no próprio sistema e, com tantas atitudes voltadas para a celeridade

de Janeiro: Renovar, 2006, p. 37 e seguintes

8 A necessária celeridade processual não é uma promessa nova. Há tempos se fala em duração razoável do processo. Nesse sentido, no Brasil, dentre outros, Dinamarco, Tucci, Carlos Alberto Alvaro de Oliveira, Bedaque. 
e a aplicação adequada do direito, acreditamos realmente entrar em uma nova fase que pode ser denominada efetivista.

A ponderação de valores ou interesses ganhou espaço considerável na doutrina e na jurisprudência e essa perspectiva pós-positivista e axiológica foi sistematizada tendo em conta um catálogo de princípios de interpretação especificamente constitucional: a supremacia da Constituição, a presunção da constitucionalidade das leis e dos atos emanados do poder público, a interpretação conforme a constituição, a unidade da constituição, a razoabilidade e a efetividade, pressupostos. ${ }^{9}$

Aliás, a efetividade tanto no âmbito privado quanto no âmbito público é um fator que elimina a insegurança jurídica. Todo o direito passa por movimentos reformistas e o que se nota é a necessária velocidade para acompanhar uma evolução nunca esperada. Procedente ou improcedente, pelo menos há uma decisão. A demora é um fator que aflige muitas pessoas, ainda que indiretamente.

Ao se falar em efetivismo jurídico se está a fazer alusão a um caminho de desburocratização e deformalização, mantendose um mínimo necessário e legitimante da função jurisdicional, sem excessivos recursos e meios de recusa amparados em lei.

O importante é se chegar a um mínimo de garantias efetivas de funcionamento da jurisdição e, no caso do direito civil, o mínimo de garantias de que haverá a observância dos direitos fundamentais, mas com resultados úteis e tempestivos.

9 Luis Roberto Barroso. Interpretação e aplicação da Constituição. São Paulo: Saraiva, 2007, p. 32 e ss. 
Ao se discutir o direito ao esquecimento se está também pensando dentro de um contexto efetivista.

Para pensar em direito ao esquecimento ou o "right to be alone", temos que pensar nos direitos fundamentais e em seu concreto funcionamento no sistema, ponderando valores e partindo da razoabilidade e proporcionalidade.

Sobre o dever de suprimir informações divulgadas no ambiente virtual, há recentíssimas decisões que começam a traçar novos paradigmas de responsabilidade civil, mas dentro de um contexto efetivista, tornam efetivos os direitos fundamentais.

Dentre os temas tratados, é vedado o anonimato:

" 26 . A vedação constitucional ao anonimato encontrase, assim, intimamente relacionada à proteção constitucional aos direitos de personalidade, que tem por princípio a dignidade da pessoa humana, um dos fundamentos da república Federativa do Brasil, consoante art. $\mathbf{1}^{\circ}$, inciso II, da Constituição Federal.

27. Dentre os direitos de personalidade está o direito à honra e à imagem, aquela tem, ainda, uma dupla face, pois além de ser o direito que toda pessoa tem de ser respeitada perante os outros (objetiva), abarca o direito de ser respeitado perante si mesmo, o apreço que cada um tem de si (subjetiva). A imagem, por sua vez, é a representação física de cada um, sua aparência in natura, e abarca o direito que cada um tem de controle sobre seu signo físico.

28. Portanto, a vedação ao anonimato na manifestação do pensamento, ou ainda em denúncias apócrifas tem por finalidade a preservação de direitos de personalidade, ao possibilitar a responsabilização em caso de abuso e ofensa a tais direitos." (HC 107401, Relator(a): Min. 
DIAS TOFFOLI, julgado em 23/02/2011, publicado em PROCESSO ELETRÔNICO DJe-041 DIVULG 01/03/2011 PUBLIC 02/03/2011, grifos nossos)

E ainda:

ANONIMATO-NOTÍCIADE PRÁTICACRIMINOSA - PERSECUÇÃO CRIMINAL - IMPROPRIEDADE. Não serve à persecução criminal notícia de prática criminosa sem identificação da autoria, consideradas a vedação constitucional do anonimato e a necessidade de haver parâmetros próprios à responsabilidade, nos campos cível e penal, de quem a implemente. Após o voto dos Ministros Marco Aurélio, Relator, e Eros Grau deferindo o pedido de habeas corpus, pediu vista dos autos o Ministro Carlos Britto. Falou pelo paciente o Dr. Nathanael Lima Lacerda e pelo Ministério Público Federal o Subprocurador-Geral da República, Dr. Paulo de Tarso Braz Lucas.1 ${ }^{\text {a }}$ Turma, 15.02.2005. Decisão: Renovado o pedido de vista do Ministro Carlos Britto, de acordo com o art. $1^{\circ}, \S 1^{\circ}$, in fine, da Resolução n. 278/2003. $1^{\text {a }}$ Turma, 22.03.2005. Decisão: Adiado o julgamento por indicação do Ministro Carlos Britto. $1^{\mathrm{a}}$ Turma, 05.04.2005. Decisão: Continuando o julgamento, após os votos do Ministro Carlos Britto, indeferindo o pedido de habeas corpus, do Ministro Eros Grau, que ratificava o seu voto anterior, deferindo a ordem e Cezar Peluso no mesmo sentido, pediu vista dos autos o Ministro Sepúlveda Pertence, Presidente. $1^{\text {a }}$ Turma, 26.04.2005. Decisão: Renovado o pedido de vista do Ministro Sepúlveda Pertence, de acordo com o art. $1^{\circ}, \S 1^{\circ}$, in fine, da Resolução n. 278/2003. $1^{\text {a }}$ Turma, 07.06.2005. Decisão: Adiado o julgamento por indicação do Ministro Sepúlveda Pertence. $1^{\text {a }}$ Turma, 21.06.2006. Decisão: Por maioria de votos, a Turma deferiu o pedido de habeas corpus, nos termos 
do voto do Relator; vencido o Ministro Carlos Britto. Não participaram desta Sessão os Ministros Cezar Peluso e Eros Grau, transferidos para a Segunda Turma. Não participaram deste julgamento o Ministro Ricardo Lewandowski e a Ministra Cármen Lúcia por não pertencerem à Turma à época do início do julgamento. (1 ${ }^{\mathrm{a}}$. Turma, 07.08.2007. HC 84827 / TO TOCANTINS, Relator(a): Min. MARCO AURÉLIO, Julgamento: 07/08/2007).

No mesmo sentido entende o E. Superior Tribunal de Justiça:

Por justa causa entende-se o motivo legal ou o suporte probatório mínimo em que se baseie a acusação, não servindo para tal mister uma mera cartadenúncia anônima na qual se fundou a instauração do procedimento, mormente porque o ordenamento jurídico do País veda a prática do anonimato, nos termos do inciso IV do art. $5^{\circ}$ da Constituição Federal. (REsp 1074302/SC, Rel. Ministro BENEDITO GONÇALVES, PRIMEIRA TURMA, julgado em 20/04/2010, DJe 03/08/2010)

Acerca da obrigatoriedade de retirada de informações não autorizadas (STJ - RECURSO ESPECIAL: REsp 1306066 MT 2011/0127121-0, Relator Min. Sidnei Beneti)

RECURSO ESPECIAL. DIREITO DO CONSUMIDOR. PROVEDOR. MENSAGEM DE CONTEÚDO OFENSIVO. RETIRADA. REGISTRO DE NÚMERO DO IP. DANO MORAL. AUSÊNCIA. PROVIMENTO. 
1- No caso de mensagens moralmente ofensivas, inseridas no site de provedor de conteúdo por usuário, não incide a regra de responsabilidade objetiva, prevista no art. 927, parágrafo único, do Cód. Civil/2002, pois não se configura risco inerente à atividade do provedor. Precedentes.

2- É 0 provedor de conteúdo obrigado a retirar imediatamente 0 conteúdo ofensivo, pena de responsabilidade solidária com 0 autor direto do dano.

3- O provedor de conteúdo é obrigado a viabilizar a identificacão de usuários, coibindo o anonimato; o registro do número de protocolo (IP) dos computadores utilizados para cadastramento de contas na nternet constitui meio de rastreamento de usuários, que ao provedor compete, necessariamente, providenciar.

4- Recurso Especial provido. Ação de indenização por danos morais julgada improcedente. (grifos nossos).

Como visto, não há especificamente regulamentação sobre o direito ao esquecimento, mas decisões que nos podem levar ao delineamento de situação em que, aplicando-se a razoabilidade e a proporcionalidade, ter-se-á a possibilidade de excluir informações, preservando-se a pessoa e os direitos fundamentais.

\section{CONCLUSÕES}

É possível delinear a partir do quanto explanado, das normas jurídicas e de recente entendimento de nossos tribunais que: 
a. É vedado o anonimato;

b. Em casos de informações pessoais, sem interesse público ou jornalístico, pode a pessoa exigir sua retirada;

c. Em caso de conteúdo ofensivo, a comunicação da pessoa é suficiente para a sua exclusão;

d. Ainda que o direito à informação seja protegido constitucionalmente, há limites para o seu exercício e conteúdo não pode gerar um prejuízo pessoal desproporcional e tratamento degradante ao sujeito;

e. Em casos de crime, a manutenção da informação não pode gerar ainda mais constrangimento à vítima ou ser mantida além da pena do condenado;

f. Não havendo condenação, respeitando-se o princípio da inocência, é importante ter limites para evitar a destruição da imagem de um possível inocente;

g. Nos casos em que houver sigilo e investigação criminal é possível limitar a informação divulgada.

Para se pensar em direito ao esquecimento ou o "right to be alone", temos de pensar nos direitos fundamentais e em seu concreto funcionamento no sistema, ponderando valores e partindo da razoabilidade e proporcionalidade.

Ou se admite a limitação, a exclusão de eventuais erros, a não utilização de determinadas informações para a discriminação, ou serão colocados de lado os direitos fundamentais, sempre afastando, também, qualquer forma de censura. 


\section{REFERÊNCIAS}

BARROSO, José Roberto. O direito constitucional e a efetividade de suas normas. Rio de Janeiro: Renovar, 2006.

\section{. Interpretação e aplicação da Constituição. São}

Paulo: Saraiva, 2007.

CASTELLS, Mannuel. A Sociedade em Rede: do Conhecimento à Política. Disponível em: <http://www.egov.ufsc.br/portal/sites/ default/files/anexos/a_sociedade_em_rededo_conhecimento_a_ acao_politica.pdf.>.

MORAES, Alexandre de. Constituição do Brasil Interpretada e Legislação Constitucional. Editora Jurídico. São Paulo: Atlas.

SILVA. José Afonso da. Curso de Direito Constitucional Positivo. 14 ed. São Paulo: Malheiros editores, 1997. 